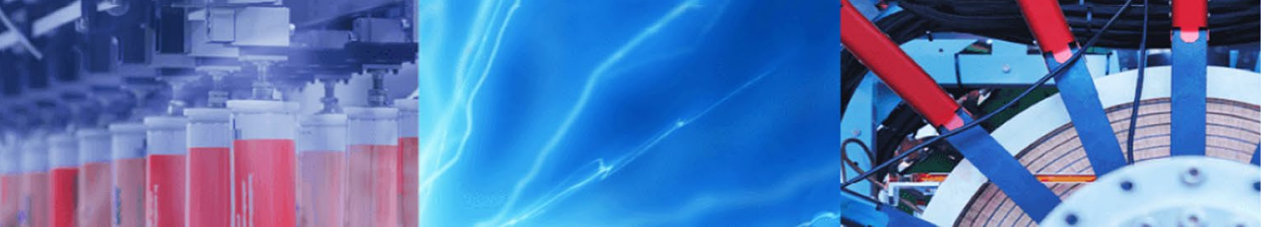

Research Article

\title{
System-wide joint-dynamic-response approach to water quality evaluation in distribution networks with multiple service reservoirs and pumps
}

\author{
Tiku T. Tanyimboh ${ }^{1}$ (D) Alemtsehay G. Seyoum ${ }^{2}$
}

Received: 24 September 2020 / Accepted: 22 February 2021 / Published online: 12 March 2021

(c) The Author(s) 2021 OPEN

\begin{abstract}
Rigorous system-wide aggregated water quality performance indices for water distribution networks are lacking in the literature due to complexities associated with high dimensional spatial and temporal water quality data. Water quality considerations unavoidably increase performance evaluation difficulties considerably. The formulation developed in this article addresses the post-extended period simulation high-dimensional data challenges. A system-wide joint-dynamicresponse approach to water quality evaluation is introduced that accounts for spatial and temporal variations in nodal demands and the respective time-varying hydraulic and water quality properties of multiple service reservoirs. Effective comparisons of the water quality response of service reservoirs and their effects were achieved. This includes individual reservoirs and the combined effects of multiple reservoirs. Service reservoirs and the nodes they supply were particularly vulnerable from the standpoint of water quality. The role of the network's topology considering water quality risks was revealed also. The correlation between the medians and flow-weighted daily means of the water quality parameters was very strong $\left(R^{2} \geq 0.994\right)$ for the service reservoirs considered. Thus, the median could be useful as a practical performance surrogate in design optimization procedures. Finally, there seems to be an association between the flow-weighted daily means and overall hydraulic effectiveness of service reservoirs.
\end{abstract}

Keywords Service reservoir · Water distribution pipe network · Water quality · Residual chlorine · Disinfection by-products - Gastrointestinal illness

\section{Introduction}

Service reservoirs in water distribution networks are vital, as the service providers have a duty to maintain a continuous and adequate supply of water. Service reservoirs provide extra operational flexibility to cope with variations in demand and major unexpected failures, e.g. power outages, pump failures and firefighting $[8, p$. 120-122]. They increase resilience, hydraulic reliability and redundancy-characterized by component failure tolerance due to surplus flow carrying capacity and alternative supply paths between the supply and demand nodes $[2$, $65,66]$. Also, service reservoirs can help achieve economical designs based on the life cycle costs.

Within the distribution system, service reservoir often refers to surface or underground storage while water tower or elevated tank often refers to elevated storage [63, AWWA 2013]. In this article, tanks and service reservoirs are

Supplementary Information The online version contains supplementary material available at https://doi.org/10.1007/s42452-021-04410 -0 .

Tiku T. Tanyimboh, tiku.tanyimboh@wits.ac.za; Alemtsehay G. Seyoum, alemgm2002@yahoo.com | ${ }^{1}$ School of Civil and Environmental Engineering, University of the Witwatersrand, Johannesburg, Private Bag 3, WITS 2050, South Africa. ${ }^{2}$ SWS Consultancy, P.O. Box 11351 , Addis Ababa, Ethiopia. 
used interchangeably in an inclusive manner for reservoirs, elevated tanks and stand pipes within the distribution system (AWWA 2013). Nevertheless, all the storage facilities in the benchmark Anytown network considered here are called tanks.

Service reservoirs influence water quality by increasing the residence time, i.e. the time of travel from the treatment plant to the node under consideration. Water quality may deteriorate as a result, due to the loss of disinfectant, increase in the concentration of disinfection by-products (DBPs) and microbial re-growth [11, 17, 19]. DBPs, e.g. trihalomethanes and haloacetic acids, are produced from the reactions of chlorine with natural organic compounds in water $[17,41]$ and are associated with adverse health effects $[6,21,22,24]$.

Therefore, to prevent the re-growth of bacteria and other organisms, enough residual chlorine should be retained in the distribution system [68, p. 458]. However, Tinker et al. [67] observed that a disinfectant residual is not always present in all parts of a distribution system, and cases of gastrointestinal illness have been linked to contamination of water in the distribution network in a number of studies [36, 37, 54].

Attention on the distribution system as a source of water-borne illness is, therefore, increasing $[45,75]$. Payment et al. [38] reported on the contribution of the distribution system to endemic gastrointestinal disease related to drinking water. Egorov et al. [14] and Levy et al. [32] considered the association between the residence time and incidence of gastrointestinal illness. Hunter et al. [27] considered the association between events leading to pressure loss in the distribution system and incidence of gastrointestinal illness [7, 15, 29, 30]. Bylund et al. [9] studied the association between gastrointestinal illness and the factors affecting drinking water quality.

The residence time is sensitive to the location of the service reservoir and operating policies adopted $[16,20$, 63, p. 139]. Edwards and Maher [13] observed that the location may influence water quality more than modifying the service reservoir to improve mixing. The conventional design practice suggests that service reservoirs should be located close to the areas that have the highest water demands [34]. However, the competing requirements are very complex.

Inefficient reservoir design may increase the capital and operating costs and residence times. Kurek and Ostfeld [31] used a multi-objective optimization approach that considered water quality, the operating costs of pumps and service reservoir sizing costs. However, the locations of the tanks were not optimized. Basile et al. [5] developed a multi-criteria approach that did not incorporate water quality or optimize service reservoir design. Farmani et al. [16] considered the total design and operation cost and locations of the service reservoirs along with water age and system resilience. Prasad and Tanyimboh [40] similarly considered the system's resilience properties including flow entropy [52, 62], but water quality was not addressed. Siew et al. [58] introduced a novel service reservoir depletion criterion. Siting of the service reservoirs was optimized but water quality was not included in the formulation. Prasad [39] and Atkinson et al. [1] addressed the total cost including service reservoir location and sizing without considering water quality in the design optimization phase. Shokoohi et al. [53] emphasized the need to address water quality at the design stage, but their optimization model did not include service reservoirs. Hallmann and Suhl [23] did not include water quality in their service reservoir optimization model or the subsequent verification by simulation.

Studies on the deleterious effects of service reservoirs and a clear understanding of the system-wide response are lacking. Optimization models for water distribution networks with multiple service reservoirs have not addressed water quality concerns adequately, and rigorous comparisons of candidate solutions are not available [26]. A quantified robust framework [26] will help to improve: (a) investment decisions [59],(b operational control [59], and (c) the development of water quality-based design optimization models [18, 28]. While previous investigations considered the individual service reservoirs or demand nodes in isolation, this article develops and demonstrates the benefits of a system-oriented approach to the evaluation of water quality that transcends the single-event regulatory compliance paradigm. Also, water quality considerations increase the performance evaluation complexity levels enormously. The system-wide joint-dynamic-response formulation proposed addresses the challenges associated with high-dimensional data.

Indeed, the Battle of the Water Networks II [33] described vividly the difficulties of high dimensionality and computational complexity and how they were addressed variously through: engineering experience,parallel computing; reducing the number of decision variables; reducing the range of possible values for each decision variable; skeletonizing the network; sequential optimization; zone-by-zone design; and stage-wise optimization (e.g. installing backup diesel generators as the final stage of the design process). The weighted average of the water age at the demand nodes above a threshold of $48 \mathrm{~h}$ was used as a practical water quality indicator. Even with simplistic or no water quality considerations the hydraulic design problem was extremely complex. This illustrates the urgent need for rigorous and practical methods of water quality evaluation for decision making and design purposes. 


\section{Overview of water quality modelling of distribution networks}

The water quality equations combine the principles of conservation of mass and reaction kinetics for the reactants under consideration. The first order reaction kinetics approach in EPANET 2 was used herein for illustration purposes. The system of equations is solved numerically in EPANET 2 using a discrete volume element method [42]. However, without loss of generality, it may be swapped with any suitable alternative as required, depending on the emphasis of the investigation at hand, i.e. EPANET-MSX or -PMX, CFD (computational fluid dynamics), etc. The focus herein is not the water quality simulation model per se but the system-wide aggregation of the results to assist with high dimensional data challenges in decision making and design optimization models that has not been addressed hitherto.

The reactions of chlorine and THMs (trihalomethanes) are modelled as in Eqs. 1 and 2, respectively, for the bulk flow, and Eq. 3 for the pipe wall.

$\partial C_{C l} / \partial t=-k_{b} C_{c l}$

$\partial C_{T H M} / \partial t=k_{b}\left(C_{L}-C_{t h m}\right)$

$\frac{\partial C}{\partial t}=\frac{2 k_{w} k_{f} C}{R\left(k_{w}+k_{f}\right)}$

where $C_{C l}$ is the chlorine concentration; $k_{b}$ is the reaction rate constant in the bulk flow; $t$ is the time; $C_{T H M}$ is the THM concentration; $C_{L}$ is the limiting THM concentration; $k_{\mathrm{w}}$ is the wall reaction rate constant [Length/Time]; $k_{f}$ is the radial mass transfer coefficient [Length/Time] that depends on the molecular diffusivity [Length ${ }^{2} /$ Time] of the reactive species and the turbulence of the flow [42], $R$ is the pipe radius; and $C$ is the reactant concentration in the bulk flow.

The equation for transport in a pipe based on advection is

$\frac{\partial C_{i}}{\partial t}=-u_{i} \frac{\partial C_{i}}{\partial x}+r_{i} ; \quad \forall i$

where $C_{i} \equiv C(i, x, t)$ is the reactant concentration in pipe $i$ at location $x$ at time $t ; u_{i} \equiv u(i, t)$ is the mean flow velocity in pipe $i$ at time $t$; and $r_{i} \equiv r\left(C_{i}\right)$ is the rate of reaction. The equation assumes that longitudinal dispersion [69] is negligible.

Mixing in service reservoirs is assumed to occur under completely mixed conditions [11]. The mass balance equation for the sth service reservoir is
$\frac{\partial\left(V_{s} C_{s}\right)}{\partial t}=\sum_{i \in I_{s}}\left(Q p_{i} C(i, x, t)_{x=L_{i}}\right)-\sum_{j \in O_{s}} Q p_{j} C_{s}+r_{s} ; \quad \forall s$

where $V_{s} \equiv V(s, t)$ and $C_{s} \equiv C(s, t)$ are, respectively, the volume in storage and reactant concentration at time $t ; l_{s}$ and $O_{s}$ represent the links with flow to and from the reservoir, respectively; and $r_{s} \equiv r\left(C_{s}\right)$ is the rate of reaction.

Similarly, mixing at the junctions of the pipes assumes that mixing is complete and instantaneous. The mass balance equation for the junctions is

$$
\left(\sum_{j \in I_{n}} Q p_{j}+Q_{e}\right) C(i, x, t)_{x=0}=\sum_{j \in I_{n}}\left(Q p_{j} C(j, x, t)_{x=L_{j}}\right)+Q_{e} C_{e} ; \quad \forall i \in O_{n}, \forall n
$$

where $j$ and $i$, respectively, represent the pipes with flow entering and leaving node $n . I_{n}$ and $O_{n}$, respectively, represent the sets of pipes with flow entering and leaving node $n ; L_{j}$ is the length of pipe $j ; Q p_{j}$ is the flow rate in pipe $j ; Q_{e}$ and $C_{e}$ are, respectively, the volumetric flow rate and reactant concentration of any external flow into the network, at node $n$.

\section{Upgrading requirements and the networks investigated}

\subsection{Network upgrading requirements considered}

The 'Anytown' network shown in Fig. 1 [73] was considered for illustration purposes. Table A1 in the Supplementary Materials shows the nodal demands. The main objective in the network's specifications was to provide the most economical design. The options included cleaning and lining the existing pipes, laying new pipes, and paralleling existing pipes. Up to two new service reservoirs could be added. Each node in the network could be considered a potential location for a new reservoir, except for the nodes with the existing reservoirs. Three identical pumps in parallel supply water from the treatment plant; up to two more could be added. Two existing tanks, called Tank $41 \mathrm{E}$ and $42 \mathrm{E}$ herein, are at node 14 and 17, respectively.

All tanks were to empty and refill during the daily operating cycle. The demands included the averageday, instantaneous peak and three fire-fighting flows. The minimum residual heads at the demand nodes for the average-day, instantaneous peak and fire-fighting flows were $28.12 \mathrm{~m}, 28.12 \mathrm{~m}$ and $14.06 \mathrm{~m}$, respectively. The instantaneous peak and two-hour fire-fighting flows would be met with the tanks operating at their low levels and one pump out of service. 
Fig. 1 Network topology. Existing tanks 41 and 42 are called $41 E$ and $42 E$ herein. Identifiers of nodes and pipes are as indicated

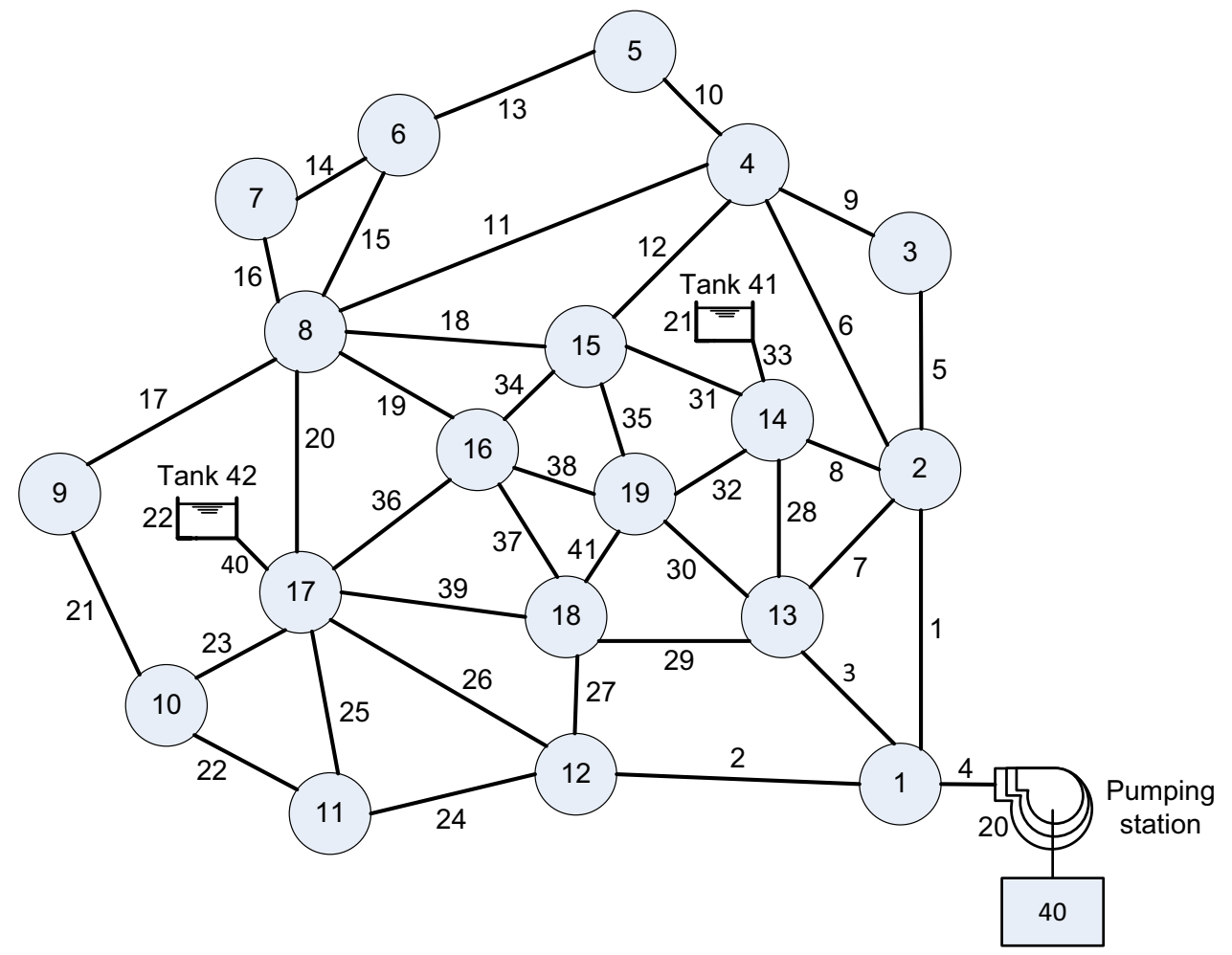

Water treatment plant

\subsection{Brief description of the networks assessed}

Four of the best solutions in the literature for the Anytown network were assessed (Table A2 in the Supplementary Materials). Walters et al.'s [74] solution costs $\$ 10.91$ million. It has two new tanks: Tank $5 \mathrm{~N}$ at node 5 and Tank $12 \mathrm{~N}$ at node 12. Walters et al. [74] surmised that a more expensive alternative solution was preferable based on water quality considerations. Only the solution with a total cost of \$10.91 million was considered here. Prasad's [39] solution costs $\$ 10.59$ million. It has two new tanks: Tank $170 \mathrm{~N}$ at node 9 and Tank $150 \mathrm{~N}$ at node 16.

Solution 1 has a total cost of $\$ 10.31$ million, with a new tank at node 7 (Tank $7 \mathrm{~N}$ ). Solution 2 has a total cost of $\$ 10.41$ million, with a new tank at node 6 (Tank $6 \mathrm{~N}$ ). The new tanks in Solution 1 and 2 are identical except for their locations and emergency storage fractions [58]. The emergency storage fraction is the ratio of the emergency storage volume to the total reservoir capacity. The details of the pipes and new tanks are in Table A3 and A4, respectively, in the Supplementary Materials.

Walters et al's solution utilizes only two pumps that operate continuously for $24 \mathrm{~h}$. Prasad's solution utilizes three pumps two of which operate continuously for $24 \mathrm{~h}$ while the third operates for $12 \mathrm{~h}$ from 06:00 a.m. to 18:00 p.m. Solution 1 utilizes three pumps, with two operating continuously for $24 \mathrm{~h}$ while the third operates for nine hours from
09:00 a.m. to 18:00 p.m. Solution 2 utilizes three pumps, with two operating continuously for $24 \mathrm{~h}$ while the third operates for nine hours from 06:00 a.m. to 03:00 p.m.

Among the above-mentioned solutions, Siew et al.'s [58] approach (Fig. 2) stands out in the literature as it achieved numerous previously unidentified least-cost designs for the Anytown and other benchmark problems [57]. Moreover, it has been shown that, computationally, it is highly competitive. Thus, Solution 1 and 2 and Prasad [39] are the best in the literature, based on the hydraulic requirements and cost. In other words, they are the most competitive feasible solutions in terms of the total cost. The maximum difference in cost between these solutions is only $2.6 \%$ and, to date, besides the total cost, it has proved particularly challenging to compare and rate them in a convincing way from the perspective of water quality. On the other hand, Walters et al. [74] is ranked fifth in the literature in terms of the total cost (Table A2) (Supplementary Materials). This solution was chosen because it was thought to be slightly less competitive, compared to the three best solutions. Accordingly, it was thought that Walters et al. [74] had the potential to reveal any inconsistencies in the results achieved, relative to Prasad and Solution 1 and 2.

Also, the total number of new tanks added and their locations were considered. Two solutions have two new tanks (Prasad [39] and Walters et al. [74]) and two solutions 
have one new tank (Solution 1 and 2). The aim was to avoid an imbalance in the total number of tanks in each solution.

Furthermore, Vamvakeridou-Lyroudia et al. [72] whose total cost is $\$ 10.63$ million is the fourth most economical solution in the literature. It has two new tanks whose locations are identical to Prasad [39]. Accordingly, Vamvakeridou-Lyroudia et al. [72] was not selected, as Prasad [39] is less expensive. The difference in cost between these two solutions is also the smallest, in percentage and absolute terms, among the five best solutions in the literature, i.e. $\$ 0.04$ million

\subsection{Adopted water quality simulation parameters}

Based on Seyoum et al. [49] and Carrico and Singer [10], the bulk and wall reaction rate constants were taken as $k_{\mathrm{b}}=0.5 /$ day and $k_{\mathrm{w}}=0.1 \mathrm{~m} /$ day, respectively. The required minimum chlorine concentration at the demand nodes was $0.2 \mathrm{mg} / \mathrm{L}$ [76]. Based on Seyoum et al. [49] a constant chlorine concentration of $0.6 \mathrm{mg} / \mathrm{L}$ was set at the treatment plant. The EU and UK drinking water standards specify a maximum THM concentration of $100 \mu \mathrm{g} / \mathrm{L}$ (EC 1998,HMG 2010) while the maximum concentration in the US EPA (1996) standard is $80 \mu \mathrm{g} / \mathrm{L}$. Accordingly, following Seyoum et al. [49], the limiting concentration of THM in Eq. 2 was taken as $100 \mu \mathrm{g} / \mathrm{L}$. An initial concentration of zero was assumed for THM at all the demand nodes and tanks. The hydraulic and water quality time steps were one minute each. The small hydraulic time step of one minute was selected to provide confirmation that the solutions are hydraulically feasible theoretically. The duration of the extended period simulation (EPS) was 3.0 days. The results presented here are based on the last $24 \mathrm{~h}$. This is to avoid any unstable results near the start of the simulations.

\subsection{Evaluation of water quality sub-indices based on flow-weighted arithmetic mean}

Given the spatial and diurnal variations in the nodal demands and water quality, sub-indices for the quality of water at a location (demand node or service reservoir) and the entire network for a specified duration are useful, e.g. as part of a decision support system. Accordingly, aggregation based on the flow-weighted arithmetic mean was considered herein.

For the nth demand node and sth service reservoir, the overall water quality sub-indices, $I_{n}$ and $I_{s}$ respectively, based on the flow-weighted arithmetic mean were obtained as follows.

$$
\begin{aligned}
I_{n}= & \sum_{t=1}^{N_{t}} w(n, t) C(n, t) ; \quad w(n, t)=\frac{Q(n, t)}{\sum_{t=1}^{N_{t}} Q(n, t)} ; \\
& \sum_{t=1}^{N_{t}} w(n, t)=1 ; \quad \forall n \in D \\
I_{s}= & \sum_{t=1}^{N_{t}} w(s, t) C(s, t) ; \quad w(s, t)=\frac{V(s, t)}{\sum_{t=1}^{N_{t}} V(s, t)} ; \\
& \sum_{t=1}^{N_{t}} w(s, t)=1 ; \quad \forall s \in S
\end{aligned}
$$

where the sets $D$ and $S$ comprise the demand nodes and service reservoirs, respectively, and $n, s$ and $t$ refer to the demand nodes, service reservoirs and time, respectively; $w(n, t)$ and $w(s, t)$ represent the weights for the demand nodes and service reservoirs, respective; $C(n, t)$ and $C(s, t)$ represent water quality properties, e.g. water age, at the demand nodes and service reservoirs, respectively. $N_{t}$ represents the number of observations. Thus, for simplicity, $t$ refers to the observation number and corresponding time due to the one-to-one mapping. $Q(n, t)$ and $V(s, t)$ represent the nodal volume flow rates and volumes of water in the service reservoirs, respectively.

The corresponding formulation for all the demand nodes in aggregate follows similarly.

$$
\begin{aligned}
I_{D}= & \sum_{n \in D} \sum_{t=1}^{N_{t}} w(n, t) C(n, t) ; \quad w(n, t)=\frac{Q(n, t)}{\sum_{n \in D} \sum_{t=1}^{N_{t}} Q(n, t)} ; \\
& \sum_{n \in D} \sum_{t=1}^{N_{t}} w(n, t)=1
\end{aligned}
$$

where $I_{D}$ is the water quality sub-index for all the demand nodes taken together.

Also, the sub-index $I_{R}$ for all the service reservoirs in aggregate is

$$
\begin{aligned}
I_{R}= & \sum_{s \in S} \sum_{t=1}^{N_{t}} w(s, t) C(s, t) ; \quad w(s, t)=\frac{V(s, t)}{\sum_{s \in S} \sum_{t=1}^{N_{t}} V(s, t)} ; \\
& \sum_{s \in S} \sum_{t=1}^{N_{t}} w(s, t)=1
\end{aligned}
$$

It is worth noting that the demand nodes and service reservoirs were considered separately. Thus, the set $D$ that represents the demand nodes does not include the service reservoirs. 
Table 1 Water quality results of demand nodes

\begin{tabular}{|c|c|c|c|c|c|c|c|c|c|c|c|c|}
\hline & \multicolumn{12}{|c|}{ Worst instance } \\
\hline & \multicolumn{3}{|c|}{ Solution 1} & \multicolumn{3}{|c|}{ Solution 2} & \multicolumn{3}{|c|}{ Prasad (2010) } & \multicolumn{3}{|c|}{ Walters et al. (1999) } \\
\hline & Value & Time & Node & Value & Time & Node & Value & Time & Node & Value & Time & Node \\
\hline $\begin{array}{l}\text { Chlorine-min } \\
\text { (mg/L) }\end{array}$ & 0.22 & 0600 & 7 & 0.31 & 2300 & 9 & 0.25 & 0400 & 9 & 0.18 & 0400 & 5 \\
\hline $\begin{array}{l}\text { THM-max } \\
(\mu \mathrm{g} / \mathrm{L})\end{array}$ & 49.8 & 0600 & 7 & 28.6 & 1100 & 6 & 36.8 & 0300 & 16 & 51.7 & 0400 & 5 \\
\hline \multirow{3}{*}{$\begin{array}{l}\text { Water age-max } \\
\text { (hours) }\end{array}$} & 30.8 & 0600 & 7 & 19.4 & 1100 & 6 & 25.2 & 0300 & 16 & 34.2 & 0400 & 5 \\
\hline & \multicolumn{12}{|c|}{ Flow weighted daily mean } \\
\hline & \multicolumn{3}{|c|}{ Solution 1} & \multicolumn{3}{|c|}{ Solution 2} & \multicolumn{2}{|c|}{ Prasad (2010) } & & \multicolumn{3}{|c|}{ Walters et al. (1999) } \\
\hline Chlorine (mg/L) & \multicolumn{3}{|l|}{0.48} & \multicolumn{3}{|l|}{0.48} & \multicolumn{3}{|l|}{0.49} & \multicolumn{3}{|l|}{0.49} \\
\hline $\mathrm{THM}(\mu \mathrm{g} / \mathrm{L})^{\mathrm{a}}$ & \multicolumn{3}{|l|}{8.53} & \multicolumn{3}{|l|}{$8.48^{\mathrm{a}}$} & \multicolumn{3}{|l|}{$8.10^{\mathrm{a}}$} & \multicolumn{3}{|l|}{$7.97^{\mathrm{a}}$} \\
\hline Water age (hours) & \multicolumn{3}{|l|}{4.17} & \multicolumn{3}{|l|}{4.16} & \multicolumn{3}{|l|}{3.81} & \multicolumn{3}{|l|}{3.84} \\
\hline
\end{tabular}

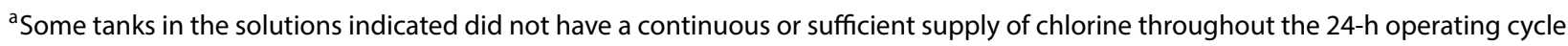

\section{Results}

Water age, chlorine and THMs were simulated for the networks in Sect. 3.2. Tables 1, 2 and 3 show the results for the demand nodes, existing and new tanks, respectively. Table 4 shows the aggregated performance of the tanks in each network, based on water quality. The results include the worst instances, medians, flowweighted daily means and correlations between the medians and flow-weighted daily means. The average durations of the 72-h simulations in EPANET 2 were $2.6 \mathrm{~s}$ for water age, $4.6 \mathrm{~s}$ for residual chlorine and $4.9 \mathrm{~s}$ for THMs on a laptop (Intel Core TM i5-2430 M, $2.4 \mathrm{GHz}$ CPU, 8.0 GB RAM). The results obtained are discussed for the new and existing tanks plus demand nodes in turn. To add some perspective, a survey of US water utilities reported average and maximum water ages in distribution networks of 1.3 days ( $31.2 \mathrm{~h}$ ) and 3.0 days ( $72 \mathrm{~h}$ ), respectively (AWWA and AwwaRF 1992).

\subsection{Water quality in the new tanks}

\subsubsection{Water age}

The flow-weighted water ages for the new tanks in Solution 1, 2 and Prasad [39], i.e. Tank $150 \mathrm{~N}$ and Tank $170 \mathrm{~N}$, were $31.4,31.5,37.2$ and $45.9 \mathrm{~h}$, respectively. The corresponding maximum water ages were $37.5,39.3,46.5$ and $53.5 \mathrm{~h}$. These results show that the new tanks in Solution 1 and 2 outperformed the new tanks in Prasad (Fig. 3). The maximum water age in Solution 2 was probably greater than Solution 1 because Solution 2 has a larger emergency storage fraction (Table A3) (Supplementary Materials). Figure 3 also shows that the maximum water ages in Solution 1 and 2 were lower than in Walters et al. [74], i.e. $42.2 \mathrm{~h}$ in Tank $5 \mathrm{~N}$.

\subsubsection{Residual chlorine}

The lowest chlorine concentrations were $0.23 \mathrm{mg} / \mathrm{L}$ for Solution 1 (14:00-18:00) and $0.22 \mathrm{mg} / \mathrm{L}$ for Solution 2 (14:00-15:00). The lowest values in Prasad [39] were mostly below $0.2 \mathrm{mg} / \mathrm{L}$. In Walters et al. $58 \%$ of the concentrations in Tank $5 \mathrm{~N}$ were below $0.2 \mathrm{mg} / \mathrm{L}$.

\subsubsection{Disinfection by-products}

The flow weighted THM concentrations of Solution 1, 2 and Prasad (Tank $150 \mathrm{~N}$ and $170 \mathrm{~N}$ ) were 43.8, 43.8, 50.5 and $59.2 \mu \mathrm{g} / \mathrm{L}$, respectively. In Walters et al. the values were 49.8 and $28.3 \mu \mathrm{g} / \mathrm{L}$ in Tank $5 \mathrm{~N}$ and $12 \mathrm{~N}$, respectively. Tank $12 \mathrm{~N}$ is relatively close to the pumping station and water treatment works, while Tank $5 \mathrm{~N}$ is at the opposite end of the network. This explains the large difference between the THM concentrations in favour of Tank $12 \mathrm{~N}$. 


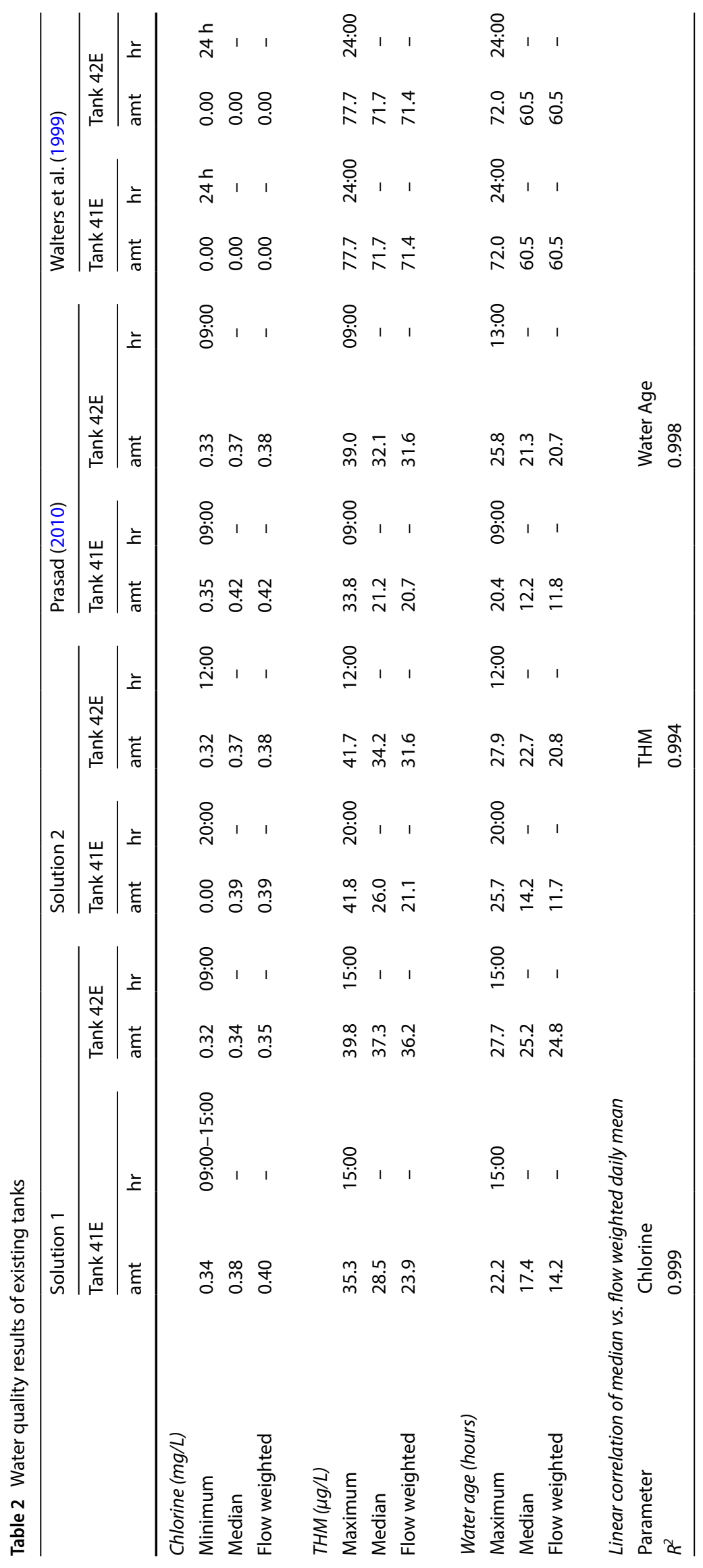


Table 3 Water quality results of new tanks

\begin{tabular}{|c|c|c|c|c|c|c|c|c|c|c|c|c|}
\hline & \multirow{2}{*}{\multicolumn{2}{|c|}{$\frac{\text { Solution } 1}{\text { Tank } 7 \text { N }}$}} & \multirow{2}{*}{\multicolumn{2}{|c|}{$\frac{\text { Solution } 2}{\text { Tank } 6 \mathrm{~N}}$}} & \multicolumn{4}{|c|}{ Prasad (2010) } & \multicolumn{4}{|c|}{ Walters et al. (1999) } \\
\hline & & & & & \multicolumn{2}{|c|}{ Tank $150 \mathrm{~N}$} & \multicolumn{2}{|c|}{ Tank $170 \mathrm{~N}$} & \multicolumn{2}{|l|}{ Tank $5 \mathrm{~N}$} & \multicolumn{2}{|c|}{ Tank $12 \mathrm{~N}$} \\
\hline & Value & Time & Value & Time & Value & Time & Value & Time & Value & Time & Value & Time \\
\hline \multicolumn{13}{|l|}{ Chlorine (mg/L) } \\
\hline Minimum & 0.23 & $14: 00-18: 00$ & 0.22 & $14: 00-15: 00$ & 0.15 & $18: 00$ & 0.09 & $17: 00$ & 0.16 & $14: 00$ & 0.31 & $15: 00$ \\
\hline Median & 0.25 & - & 0.26 & - & 0.19 & - & 0.11 & - & 0.19 & - & 0.38 & - \\
\hline Flow weighted & 0.26 & - & 0.27 & - & 0.20 & - & 0.11 & - & 0.20 & - & 0.41 & - \\
\hline \multicolumn{13}{|l|}{$\operatorname{THM}(\mu g / L)$} \\
\hline Maximum & 50.7 & $16: 00$ & 53.2 & $15: 00$ & 60.1 & $18: 00$ & 65.5 & $17: 00$ & 56.4 & $15: 00$ & 43.7 & $15: 00$ \\
\hline Median & 45.3 & - & 45.2 & - & 51.3 & - & 59.3 & - & 50.7 & - & 32.7 & - \\
\hline Flow weighted & 43.8 & - & 43.8 & - & 50.5 & - & 59.2 & - & 49.8 & - & 28.3 & - \\
\hline \multicolumn{13}{|l|}{ Water age (hours) } \\
\hline Maximum & 37.5 & $15: 00$ & 39.3 & $18: 00$ & 46.5 & $18: 00$ & 53.5 & $17: 00$ & 42.2 & $15: 00$ & 29.3 & $15: 00$ \\
\hline Median & 32.3 & - & 32.1 & - & 37.1 & - & 46.9 & - & 36.2 & - & 20.8 & - \\
\hline Flow weighted & 31.4 & - & 31.5 & - & 37.2 & - & 45.9 & - & 36.1 & - & 18.5 & - \\
\hline \multicolumn{13}{|c|}{ Linear correlation of median vs. flow weighted daily mean } \\
\hline Parameter & Chlorine & & & & & THM & & & Water Age & & & \\
\hline$R^{2}$ & 0.999 & & & & & 0.998 & & & 0.994 & & & \\
\hline
\end{tabular}

Table 4 Aggregated water quality results of all tanks

\begin{tabular}{|c|c|c|c|c|c|c|c|}
\hline \multirow[t]{2}{*}{ Solutions } & \multirow[t]{2}{*}{ Criteria } & \multicolumn{6}{|c|}{$\begin{array}{l}\text { Flow weighted daily meTank } 42 \mathrm{E} \\
\text { ans for the tanks individually and collectively }\end{array}$} \\
\hline & & Tank 41E & & Tank 41E & & Tank $7 \mathrm{~N}$ & Network $^{\mathrm{a}}$ \\
\hline \multirow[t]{4}{*}{ Solution 1} & Water age (hours) & 14.23 & & 24.78 & & 31.39 & 28.00 \\
\hline & Chlorine (mg/L) & 0.4 & & 0.35 & & 0.26 & 0.30 \\
\hline & $\mathrm{THM}(\mu \mathrm{g} / \mathrm{L})$ & 23.88 & & 36.18 & & 43.78 & 39.86 \\
\hline & & Tank 41E & & Tank 42E & & Tank $6 \mathrm{~N}$ & Network \\
\hline \multirow[t]{4}{*}{ Solution 2} & Water age (hours) & 11.74 & & 20.75 & & 31.5 & 27.53 \\
\hline & Chlorine (mg/L) & 0.39 & & 0.38 & & 0.27 & 0.30 \\
\hline & $\mathrm{THM}(\mu \mathrm{g} / \mathrm{L})$ & 21.10 & & 31.56 & & 43.81 & 39.26 \\
\hline & & Tank 41E & Tank 42E & & Tank $5 \mathrm{~N}$ & Tank $12 \mathrm{~N}$ & Network \\
\hline \multirow[t]{4}{*}{ Walters et al.(1999) } & Water age (hours) & 60.5 & 60.5 & & 36.06 & 18.42 & 43.11 \\
\hline & Chlorine (mg/L) & 0 & 0 & & 0.20 & 0.41 & 0.15 \\
\hline & $\mathrm{THM}(\mu \mathrm{g} / \mathrm{L})$ & 71.36 & 71.36 & & 49.79 & 28.34 & 55.14 \\
\hline & & Tank 41E & Tank 42E & & Tank $150 \mathrm{~N}$ & Tank $170 \mathrm{~N}$ & Network \\
\hline \multirow[t]{3}{*}{ Prasad (2010) } & Water age (hours) & 11.17 & 20.65 & & 38.08 & 45.89 & 31.37 \\
\hline & Chlorine (mg/L) & 0.42 & 0.38 & & 0.20 & 0.11 & 0.26 \\
\hline & THM $(\mu \mathrm{g} / \mathrm{L})$ & 20.66 & 31.58 & & 50.45 & 59.18 & 43.02 \\
\hline
\end{tabular}

"The tank identifiers show the results for individual tanks while "Network" refers to the tanks in aggregate 
Fig. 2 Penalty-free multiobjective genetic algorithm for Solution 1 and 2 [55]. EPANETPDX (pressure-dependent extension) [56] is embedded in the genetic algorithm for fitness evaluation. EPANETPDX simulates solutions using pressure-driven analysis that accounts realistically for any deficiencies in residual pressures at demand nodes

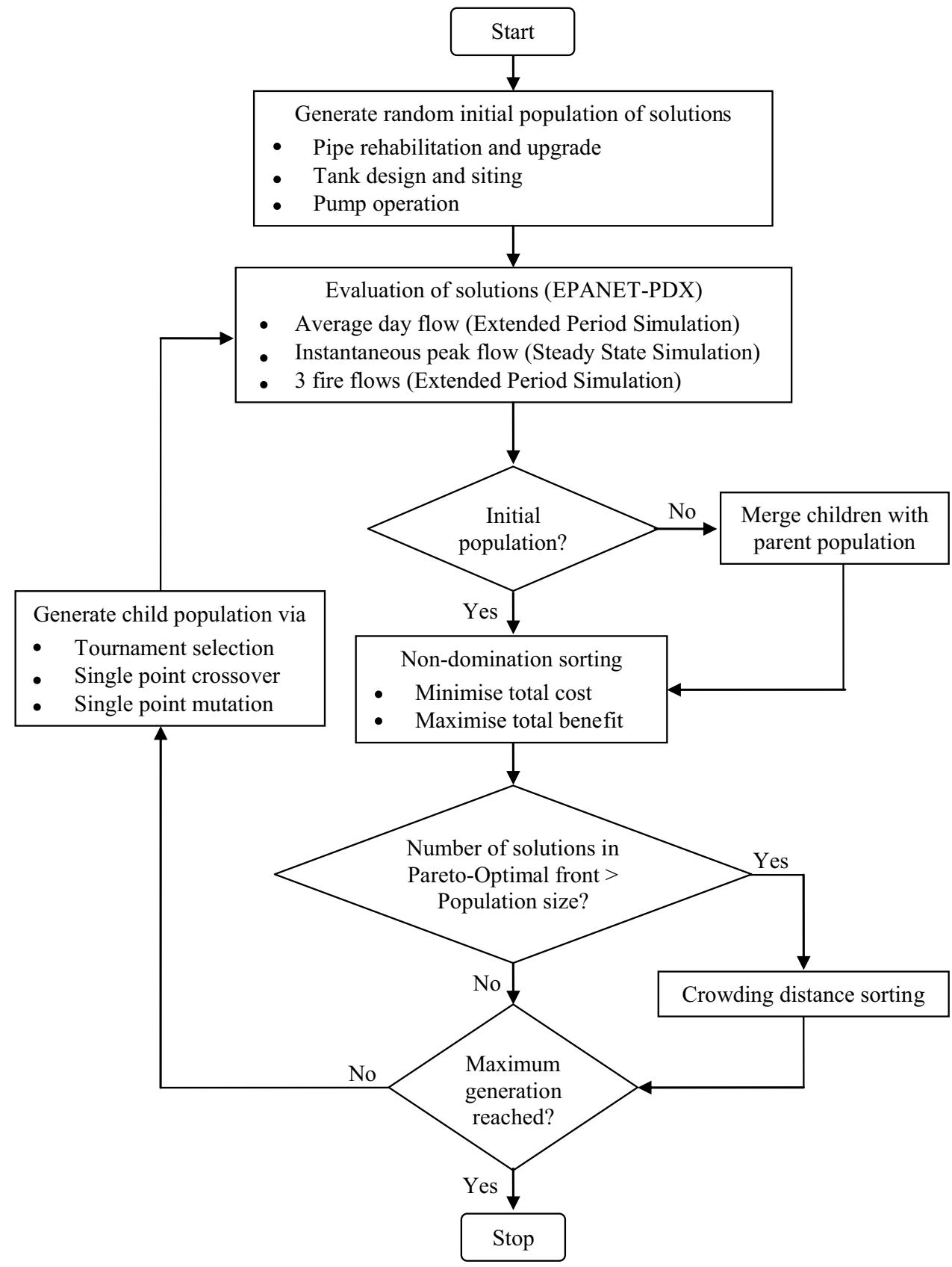

\subsection{Water quality in the existing tanks}

\subsubsection{Water age}

The respective flow-weighted water ages of Solution 1, 2, Prasad and Walters et al. for Tank 41E and 42E, respectively, were: $(14.2,24.8),(11.7,20.8),(11.8,20.7)$ and $(60.5,60.5)$ hours. The respective maximum water ages of Solution 1, 2, Prasad and Walters et al. for Tank $41 \mathrm{E}$ and $42 \mathrm{E}$, respectively, were: $(22.2,27.7),(25.7,27.9)$, $(20.4,25.8)$ and $(72.0,72.0)$ hours. These results indicate that Prasad's existing tanks had the best performance.

\subsubsection{Residual chlorine}

Figure 4 shows that the chlorine concentrations of Tank 41E in Solution 2 (19:00 and 20:00) and both existing tanks in Walters et al. (00:00 to 24:00) were unsatisfactory, i.e. $C_{C l}<0.2 \mathrm{mg} / \mathrm{L}$. The rest of the concentrations were satisfactory. This result for Solution 2 contradicts Siew et al. [58] and Seyoum et al. [49] who did not investigate Tank 41E in detail. They focused only on Tank 42E that, hitherto, had been considered particularly challenging $[39,72]$ and for which Solution 2 is better as Table 2 shows. 


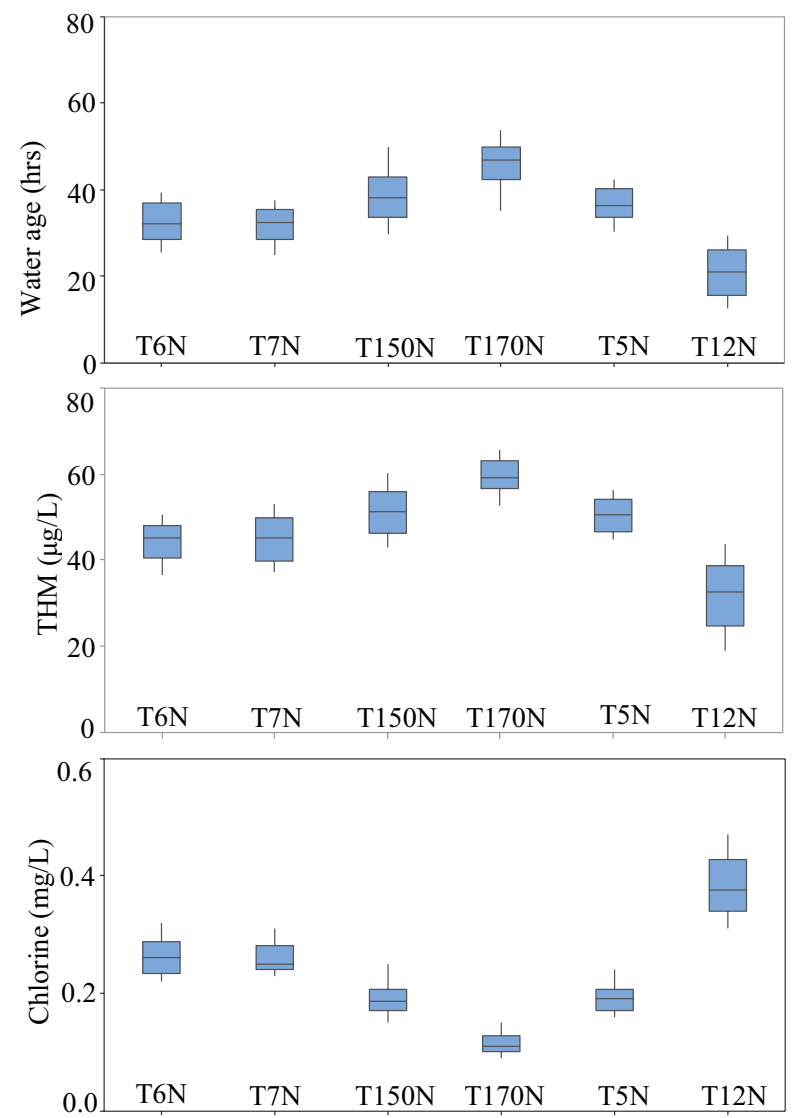

Fig. 3 Water quality of new tanks. T5N, T6N, T7N, etc. denote new tanks

On the other hand, the medians and flow-weighted means of water age, chlorine and THMs for Solution 2 are better than Solution 1 for Tank 42E. This outcome is consistent with Siew et al. [58] in which it was stated that only approximately $40 \%$ of the operational volume of Tank $42 \mathrm{E}$ of Solution 1 was utilized during the average day.

\subsubsection{Disinfection by-products}

The THM concentrations were consistent with the water ages; Prasad had the best performance, accordingly.

\subsection{Water quality at the demand nodes}

\subsubsection{Walters et al. solution}

The chlorine concentration at demand node 5 had values of $0.19 \mathrm{mg} / \mathrm{L}$ and $0.18 \mathrm{mg} / \mathrm{L}$, at 03:00 and 04:00, respectively. Node 5 is remote relative to the treatment plant.
Also, the new Tank $5 \mathrm{~N}$, whose chlorine concentration was less than $0.2 \mathrm{mg} / \mathrm{L}$ from 03:00 to 16:00, i.e. $13 \mathrm{~h}$ duration, supplies node 5 directly.

The concentration of chlorine was zero in the existing tanks throughout the $24 \mathrm{~h}$. However, the concentrations at all the other demand nodes were satisfactory, even though the aggregated chlorine concentration of all the tanks was only $0.15 \mathrm{mg} / \mathrm{L}$ (Table 4). The discrepancy between the tanks and demand nodes indicates that, hydraulically, the tanks are not well integrated in the network. The nodal flow-weighted daily means in Table 1 reinforce this idea. Even though the two existing tanks were full throughout, which is highly undesirable from a water quality perspective, the overall water quality for the demand nodes was the joint best for chlorine, second best for water age and best forTHMs. Thus, the flow-weighted means of the water quality parameters would appear to provide insights on the hydraulic connectivity effectiveness of the tanks in a network, besides the emergency and equalization storage roles.

\subsubsection{Solution 1}

The chlorine concentrations at demand nodes 5, 7 and 9 were generally lower than the rest of the nodes. These nodes are remote relative to the treatment plant and have only two incident pipes. The lower values and larger fluctuations at node 7 are attributable to the new Tank $7 \mathrm{~N}$ at node 7 (Figs. 1, 5). The maximum daily fluctuation in the chlorine concentration at node 7 was $0.30 \mathrm{mg} / \mathrm{L}$.

\subsubsection{Solution 2}

The maximum daily fluctuation in the chlorine concentration was $0.14 \mathrm{mg} / \mathrm{L}$ at node 6 , due to the new Tank $6 \mathrm{~N}$. It is interesting that the lowest daily concentration of $0.31 \mathrm{mg} / \mathrm{L}$ occurred elsewhere, i.e. at node 9 . Node 9 is remote and has only two incident pipes. The maximum daily fluctuation of $0.14 \mathrm{mg} / \mathrm{L}$ for Solution 2 represents a reduction of $53.3 \%$ relative to Solution 1 whose maximum fluctuation was $0.30 \mathrm{mg} / \mathrm{L}$. The improvements in Solution 2 relative to Solution 1 include: (a) a significant increase in the minimum daily concentration of chlorine from $0.22 \mathrm{mg} / \mathrm{L}$ to $0.31 \mathrm{mg} / \mathrm{L}$, i.e. $40.9 \%$; and (b) a significant reduction of $53.3 \%$ in the maximum daily fluctuation of chlorine. These improvements can be attributed to the innovative reservoir (tank) depletion measure that was included in Solution 2's formulation. 
Fig. 4 Water quality of existing tanks. S1, S2, P and W denote solutions

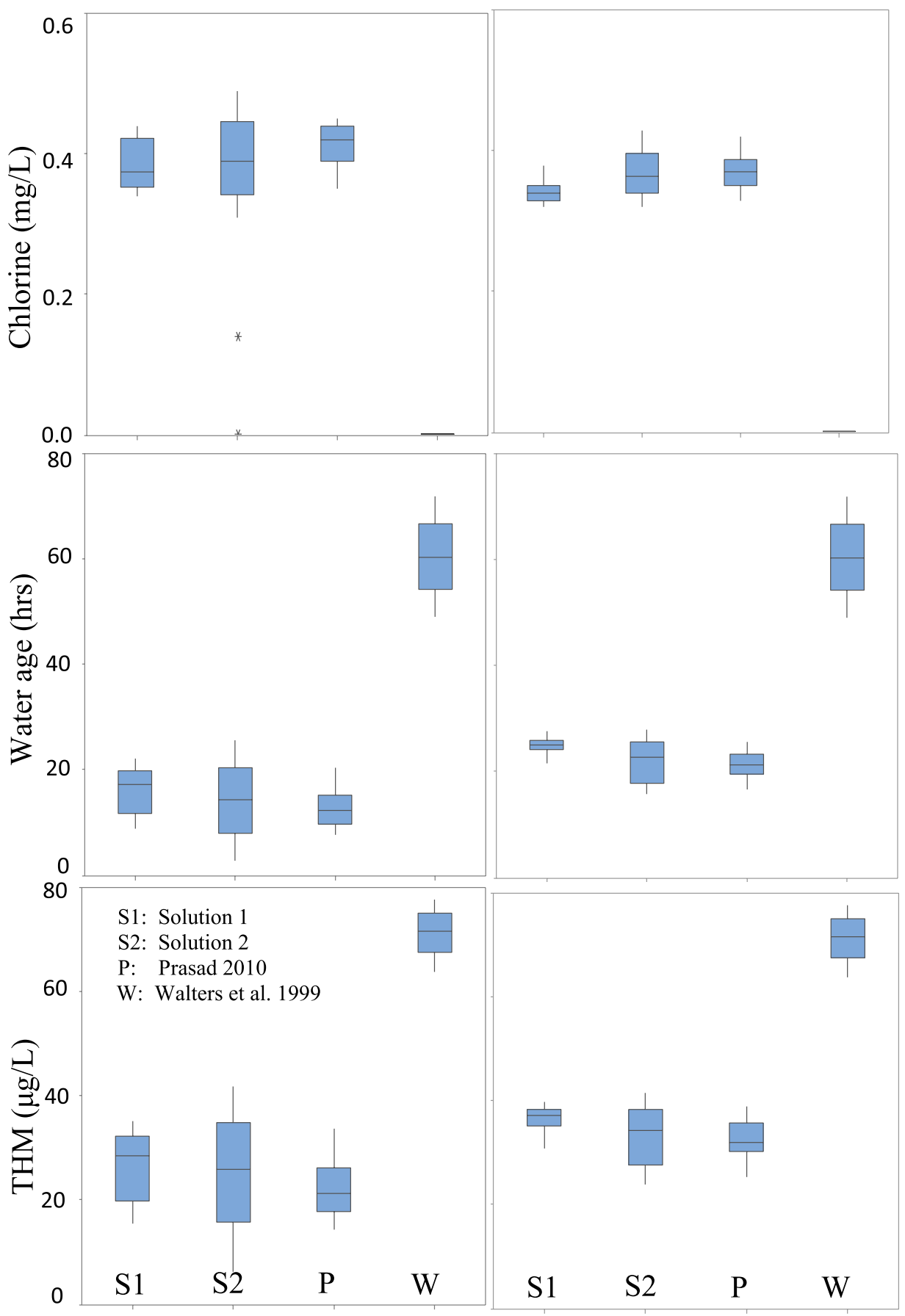

Tank 41E
Tank 42E

\subsubsection{Prasad solution}

The lowest chlorine concentration of $0.25 \mathrm{mg} / \mathrm{L}$ was at demand node 9 . The daily fluctuations at node 9 and 16 that have the new tanks were considerably more than the other demand nodes. The chlorine concentration in Tank $170 \mathrm{~N}$ (at node 9) was below $0.2 \mathrm{mg} / \mathrm{L}$ throughout the $24-\mathrm{h}$ cycle (Fig. 3). Similarly, the chlorine concentration in Tank $150 \mathrm{~N}$ (at node 16) was mostly below $0.2 \mathrm{mg} / \mathrm{L}$. However, the chlorine concentrations at demand node 16 and 9 did not fall below $0.2 \mathrm{mg} / \mathrm{L}$, as those nodes have alternative supply paths besides the new tanks. Nevertheless, the lowest concentrations at demand node 9 and 16 were considerably below the other demand nodes. 


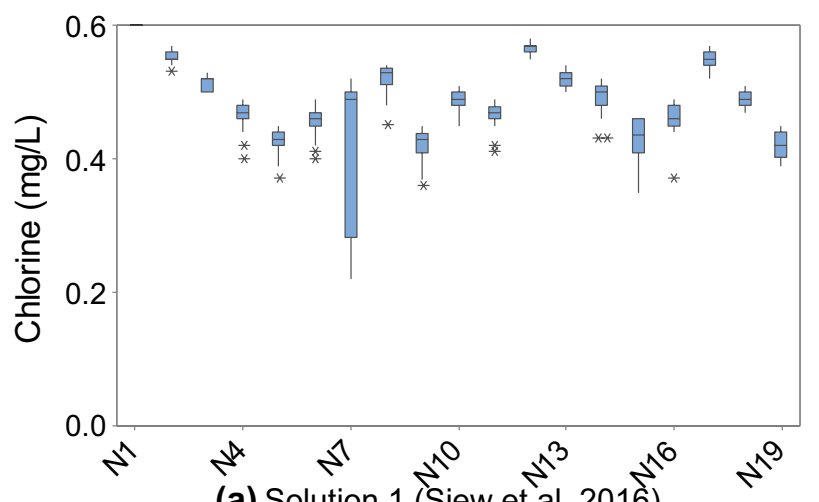

(a) Solution 1 (Siew et al. 2016)

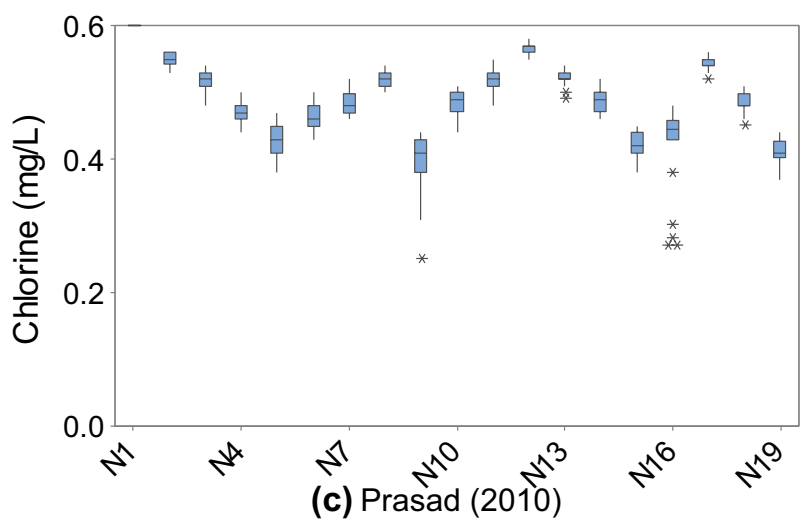

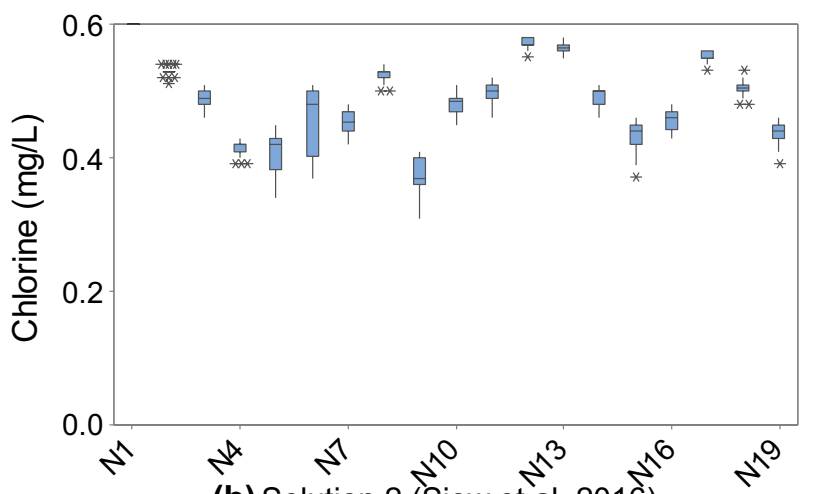

(b) Solution 2 (Siew et al. 2016)

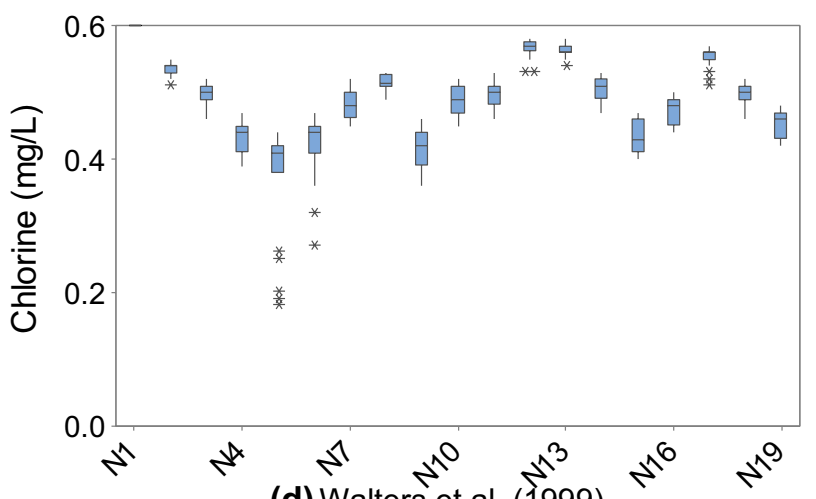

(d) Walters et al. (1999)

Fig. 5 Daily variations of chlorine concentrations of demand nodes. N1, N2, N3, ., N19 represent nodes 1 to 19

These results illustrate the importance of the reservoir location and network topology. Table 1 shows that the aggregated performance of the demand nodes was the joint best for chlorine, best for water age and second best for THMs. However, the combined performance of the tanks is the second worst in Table 4. This shows the influence of the tanks is somewhat limited and may be an indication that, besides storage, the tanks are hydraulically less integrated and effective compared to Solution 1 and 2 .

\section{Discussion}

The spatial distributions of the water age and concentrations of chlorine and THMs based on the daily demand node arithmetic means are shown in Fig. 6 . They do not seem to reveal any dominant solutions. The simple arithmetic mean (US EPA 2006), inherently, lacks robustness, as any differences in the flows or volumes that the individual concentrations pertain to are not considered. This may be one of the reasons that satisfactory integrated service reservoir design optimization models are not available yet. Huang et al. [26] stated that research on water quality reliability has generally been very simplistic and comprehensive measures and protocols were required. For example, Atkinson et al. [1] discussed the maximum and "average system water age". Nevertheless, the demand node daily arithmetic means appear to indicate possible performance outliers and gross trends in the system's response (Fig. 6).

The medians and flow-weighted means in Tables 2 and 3 suggest that the previously mentioned weaknesses in the Walters et al. and Prasad solutions are deep-seated. Furthermore, Table 4 shows that the tanks in Solution 2 have the best overall performance, followed by Solution 1 , Prasad and Walters et. al. Also, Table 1 shows that Solution 2 has the best water quality at the demand nodes. Thus, the flow weighted water quality means would appear to be able to reveal the relative efficiency of the tanks in a network.

However, Table 2 also shows that the minimum concentration of chlorine in Tank 41E in Solution 2 was zero. Therefore, Solution 2 seems marginally infeasible. Figure 4 supports this observation; the two chlorine concentration values (out of 24) that are less than $0.2 \mathrm{mg} / \mathrm{L}$ are outliers. Accordingly, Solution 2 seems to be an exemplar of a costeffective virtually feasible solution (with respect to water quality) that could thrive in a penalty-free multi-objective 


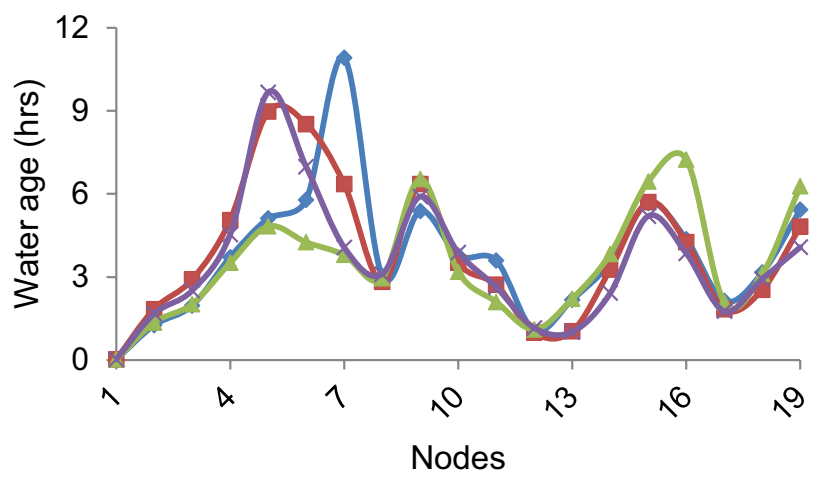

$\multimap$ Solution $1-$ Solution $2 \rightarrow$ Prasad $\leftarrow$ Walters

(a) Water age

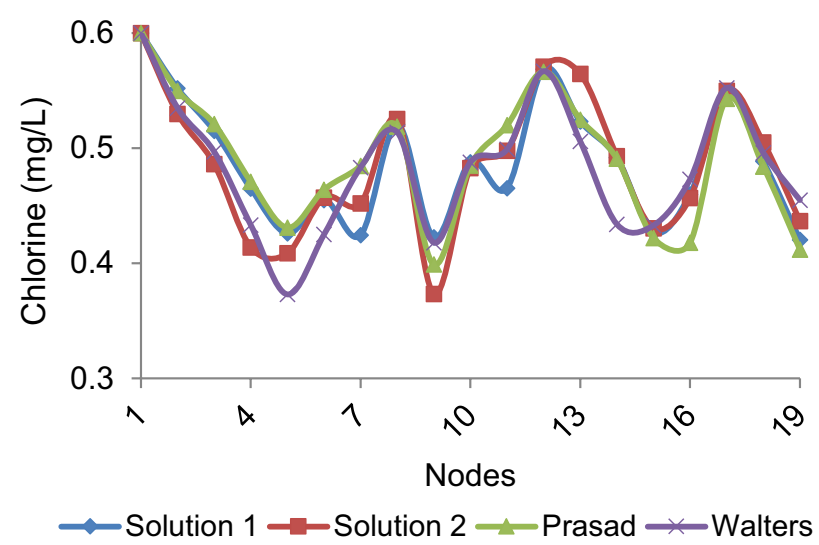

(b) Chlorine concentration

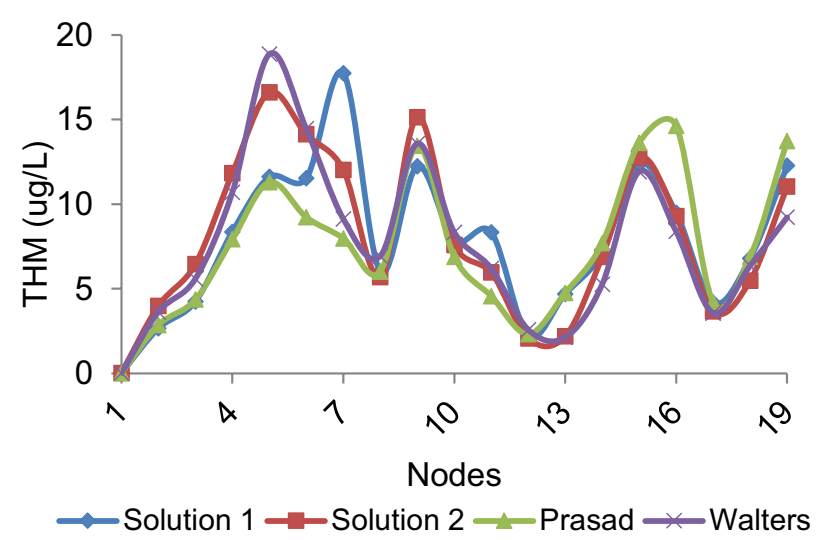

(c) THM concentration

Fig. 6 Daily averages of water quality parameters of demand nodes

evolutionary optimization framework that co-evolves subpopulations of efficient feasible and infeasible non-dominated solutions [64]. Solution 2, therefore, highlights the vital need for robust performance indicators that reveal the intrinsic properties of the system, as a unit, to complement the regulatory compliance approach based purely on the worst instances. The above-mentioned penaltyfree evolutionary optimization approach has been shown to be highly effective, based on the solution quality and computational efficiency $[43,44,57]$. Overall, Solution 1 is the best in terms of the hydraulic requirements of nodal flows and pressures, water quality regulatory compliance and total cost.

Also, the water quality results achieved are consistent with the current distribution practice, in which booster chlorination is employed at the inlets of some reservoirs (tanks) in some extensive distribution systems [68, p. 458]. Taking all the tanks and demand nodes into consideration, the worst performing nodes overall for the Walters et al. solution are the two existing tanks (Tank 41E and $42 \mathrm{E}$, Table 2) where the lowest chlorine concentrations occurred. The lowest chlorine concentration in Prasad's solution occurred in Tank $170 \mathrm{~N}$ (Table 3). The minimum chorine concentration in Solution 1 occurred at node 7 (Table 1), where Tank $7 \mathrm{~N}$ is located, while the minimum chlorine concentration in Solution 2 occurred in Tank $41 \mathrm{E}$ (Table 2).

Solution 1 and 2 have the least expensive new tanks in the literature (Table A2) (Supplementary Materials). It is, therefore, reasonable to attribute at least part of the water quality weaknesses of other solutions to the built-in, albeit hidden, surplus capacity of the new tanks. Located in an area of relatively high demand and diametrically opposite to the water treatment works, the new tanks in Solution 1 and 2 would likely improve the hydraulic capacity reliability also. The reason is that the water would be supplied from two opposite ends of the network. The foregoing observation notwithstanding, aspects relating to hydraulic capacity reliability and failure tolerance were not considered as they fall outside the scope of the research reported here.

Also, it is thought that the criterion that promoted reservoir depletion also improved the cost effectiveness by removing surplus capacity [58]. This is an indication that the novel reservoir design methodology developed by Siew et al. [58] is highly effective. The operating water levels in the new tanks in Solution 1 and 2 were $5.80 \mathrm{~m}$ and $6.42 \mathrm{~m}$ respectively, compared to $4.32 \mathrm{~m}$ and $4.69 \mathrm{~m}$, respectively, in Tank $150 \mathrm{~N}$ and $170 \mathrm{~N}$ in Prasad [39], for example. This aspect was not investigated, and additional research that includes the flow patterns in the tanks is worth considering in future.

Several minor inconsistencies in the simulation results were observed, which may be due to the single-species water quality simulation approach used. Thus, the worst instances based on water age, THM and chlorine did not coincide always. For example, an apparent phase shift of one hour for Tank $5 \mathrm{~N}$ could be because the results represent independent single-species simulations. The apparent 
anomaly could be addressed easily using a multi-species simulation model [61], for example, EPANET-MSX (multispecies extension) [50]. However, the CPU (central processing unit) simulation times would increase significantly $[47$, 48].

Furthermore, a disadvantage of the EPANET 2 THM model used in the research is that the limiting value of the THM concentration should be provided in advance at the data input or initialization stage (e.g. the nodal chlorine concentrations were all set to zero to initiate the water quality simulations). A maximum THM concentration of $100 \mu \mathrm{g} / \mathrm{L}$ was assumed herein, based on the EU and UK drinking water standards (EC 1998; HMG 2010). It was observed that the THM concentrations in the tanks did not exceed $100 \mu \mathrm{g} / \mathrm{L}$. Sohn et al. [60] proposed an alternative THM model that does not require a limiting concentration, which could be used instead, as in e.g. Seyoum and Tanyimboh [46].

Similarly, while the advection-reaction simulation model employed here neglects longitudinal dispersion, it can be substituted readily, if necessary. The methodology developed is generic and any suitable reaction kinetics approach besides the first order model in EPANET 2 may be used instead. An appraisal of various reaction kinetics approaches considering multiple species (including six species of haloacetic acids) is available in Seyoum and Tanyimboh [48] in which EPANET 2 achieved consistently good results.

\section{Conclusions}

A system-wide joint-dynamic-response approach to water quality evaluation in distribution networks with multiple service reservoirs was developed to account for the temporal and spatial variations in the nodal demands together with hydraulic and water-quality response of each service reservoir. More meaningful and instructive comparisons were thus achieved. This includes comparisons between different service reservoirs in individual solutions and across multiple solutions, and similarly the overall performance of competing solutions.

The results revealed that the correlation between the medians and flow-weighted daily means of the water quality parameters was very strong $\left(R^{2} \geq 0.994\right)$, for the 14 (fourteen) service reservoirs in the networks considered. Therefore, subject to further verification, it seems that the median could be useful as a practical performance surrogate in design optimization algorithms. Also, the results would appear to indicate that the flowweighted daily means of the water quality parameters could help provide additional insights on the hydraulic integration and effectiveness of the service reservoirs in a network, besides the emergency and equalization storage roles.

Nodal demands are non-deterministic in practice and the hyperplane that separates the system performance space into the safe and failure zones cannot be ascertained reliably from purely deterministic simulations [77]. There is, therefore, a need for robust performance indicators that reflect the system's underlying performance, to underpin those essential investigations that transcend routine regulatory compliance. There are significant differences in the four alternative networks considered, including the number of service reservoirs and their capacities, locations, modes of operation and operating water levels. Furthermore, comparisons of entirely different networks or distribution systems may be required in certain circumstances, for example, for investment planning purposes. Rigorous comparisons of high-dimensional water quality results would be required, as demonstrated here.

Finally, it was observed that the new service reservoir design methodology in Siew et al. [58] yields tanks that are both economical and hydraulically efficient. It is thus recommended for further evaluation including the explicit use of water quality design objectives. While the discussion herein considered only three water quality parameters and four Pareto-optimal candidate solutions for illustration purposes, the population size of the candidate solutions requiring fitness evaluations in each generation in an evolutionary optimization framework could be thousands or more, in an optimization problem having multiple service reservoirs and thousands of demand nodes. This is the thrust of the next phase of the research.

Funding This research did not receive any specific grant from funding agencies in the public, commercial, or not-for-profit sectors.

Availability of data and materials All the essential data are in the manuscript and supplementary materials.

Code availability EPANET 2 is free software in public domain (https ://www.epa.gov/water-research/epanet).

\section{Compliance with ethical standards}

Conflict of interest The authors declare that there is no conflict of interest.

Open Access This article is licensed under a Creative Commons Attribution 4.0 International License, which permits use, sharing, adaptation, distribution and reproduction in any medium or format, as long as you give appropriate credit to the original author(s) and the source, provide a link to the Creative Commons licence, and indicate if changes were made. The images or other third party material in this article are included in the article's Creative Commons licence, unless indicated otherwise in a credit line to the material. If material is not included in the article's Creative Commons licence and your intended 
use is not permitted by statutory regulation or exceeds the permitted use, you will need to obtain permission directly from the copyright holder. To view a copy of this licence, visit http://creativecommons .org/licenses/by/4.0/.

\section{References}

1. Atkinson S, Farmani R, Memon FA, Butler D (2014) Reliability indicators for water distribution system design: comparison. J. Water Res. PI.-ASCE 140: 160-168

2. Awumah K, Goulter I, Bhatt SK (1991) Entropy-based redundancy measures in water distribution networks. J. Hydraul. Eng.-ASCE 117: 595-614

3. AWWA (2013) Steel water-storage tanks - manual of water supply practices, M42, AWWA

4. AWWA, AwwaRF, (1992) Water industry database: utility profiles. AWWA, Denver, CO

5. Basile N, Fuamba M, Barbeau B (2008) Optimisation of water tank design and locations in water distribution systems. In: Van ZyI JE, Ilemobade AA, Jacobs HE (eds) 10th International Conference on Water Distribution Systems Analysis. Kruger National Park, South Africa, 17-20 August 2008, pp 361-373

6. Benmarhnia T, Delpla I, Schwarz L, Rodriguez MJ, Levallois $P$ (2018) Heterogeneity in the relationship between disinfection by-products in drinking water and cancer: a systematic review. Int J Env Res Pub He. https://doi.org/10.3390/ijerph15050979

7. Besner MC, Prevost M, Regli S (2011) Assessing the public health risk of microbial intrusion events in distribution systems: conceptual model, available data and challenges. Water Res 45:961-979

8. Bhave PR (2003) Optimal design of water distribution networks. Alpha Science International Ltd., Pangbourne

9. Bylund J, Toljander J, Lysén M, Rasti N, Engqvist J, Simonsson M (2017) Measuring sporadic gastrointestinal illness associated with drinking water - an overview of methodologies. J Water Health 15:321-340

10. Carrico B, Singer PC (2009) Impact of booster chlorination on chlorine decay and THM production: Simulated analysis. J Environ Eng ASCE 135: 928-935

11. Clark RM, Abdesaken F, Boulos PF, Mau RE (1996) Mixing in distribution system storage tanks: Its effect on water quality. J Environ Eng ASCE 122: 814-821

12. EC (1998) Council Directive 98/83/EC on the Quality of Water Intended for Human Consumption. Official Journal of the European Communities L330

13. Edwards J, Maher J (2008) Water quality considerations for distribution system storage facilities. J Am Water Works Ass 100:60-65

14. Egorov A, Ford T, Tereschenko A, Drizhd N, Segedevich I, Fourman V (2002) Deterioration of drinking water quality in the distribution system and gastrointestinal morbidity in a Russian city. Int J Environ Heal R 12:221-233

15. Ercumen A, Gruber JS, Colford JM (2014) Water distribution system deficiencies and gastrointestinal illness: A systematic review and meta-analysis. Environ Health Persp 122:651-660

16. Farmani R, Walters G, Savic D (2006) Evolutionary multi-objective optimization of the design and operation of water distribution network: Total cost vs. reliability vs. water quality. J Hydroinform 8:165-179

17. Ghebremichael K, Gebremeskel A, Trifunovic N, Amy G (2008) Modelling disinfection by-products: coupling hydraulic and chemical models. Water Sci. Tech-W Sup 8:289-295

18. Goyal RV, Patel HM (2017) Optimal location and scheduling of booster chlorination stations for drinking water distribution system. J Appl Water Eng Res 5:51-60
19. Grayman WM, Clark RM (1993) Using computers to determine the effect of storage on water quality. J Am Water Works Ass 85:67-77

20. Grayman WM, Clark RM, Goodrich JA (1991) The effects of operation, design and location of storage tanks on the water quality in a distribution system. In: Water Quality Modeling in Distribution Systems Conference. American Water Works Association Research Foundation and American Water Works Association, Denver, CO

21. Grellier J (2018) Comment on "Disinfection by-products in drinking water and evaluation of potential health risks of longterm exposure in Nigeria." J Environ Public Health. https://doi. org/10.1155/2018/1901429

22. Grellier J, Rushton L, Briggs DJ, Nieuwenhuijsen MJ (2015) Assessing the human health impacts of exposure to disinfection by-products: a critical review of concepts and methods. Environ Int 78:61-81

23. Hallmann C, Suhl L (2016) Optimizing water tanks in water distribution systems by combining network reduction, mathematical optimization and hydraulic simulation. OR Spectrum 38:577-595

24. Hebert A, Forestier D, Lenes D, Benanou D, Jacob S, Arfi C, Lambolez L, Levi Y (2010) Innovative method for prioritizing emerging disinfection by-products (DBPs) in drinking water on the basis of their potential impact on public health. Water Res 44:3147-3165

25. HMG (2010) Water Supply (Water Quality) Regulations. Statutory Instrument 2010 No. 994, W. 99. The Stationery Office, London

26. Huang JE, McBean EA, James W (2005) A review of reliability analysis for water quality in water distribution systems. Journal of Water Management Modeling R223-07. https://doi.org/https ://doi.org/10.14796/JWMM.R223-07

27. Hunter P, Chalmers R, Hughes S, Syed Q (2005) Self-reported diarrhoea in a control group: A strong association with reporting of low-pressure events in tap water. Clin Infect Dis 40:32-34

28. Islam N, Sadiq R, Rodriguez MJ (2013) Optimizing booster chlorination in water distribution networks: a water quality index approach. Environ Monit Assess 185:8035-8050

29. Karim MR, Abbaszadegan M, LeChevallier M (2003) Potential for pathogen intrusion during pressure transients. J Am Water Works Ass 95:134-146

30. Kirmeyer GJ, Friedman M, Martel K, Howie D, LeChevallier M, Abbaszadegan M, Karim M, Funk J, Harbour J (2001) Pathogen intrusion into the distribution system. AWWA Research Foundation and American Water Works Association

31. Kurek W, Ostfeld A (2013) Multi-objective optimization of water quality, pumps operation and storage sizing of water distribution systems. J Environ Manage 115:189-197

32. Levy K, Klein M, Sarnat SE, Panwhar S, Huttinger A, Tolbert P, Moe $C$ (2016) Refined assessment of associations between drinking water residence time and emergency department visits for gastrointestinal illness in Metro Atlanta. Georgia J Water Health 14:672-681

33. Marchi A, Salomons E, Ostfeld A et al (2014) Battle of the water networks II. J Water Res PI-ASCE. https://doi.org/10.1061/(ASCE) WR.1943-5452.0000378

34. Mays LW (1999) Water distribution systems handbook. McGrawHill, Montreal

35. Murphy LJ, Dandy GC, Simpson AR (1994) Optimum design and operation of pumped water distribution systems. Conference on Hydraulics in Civil Engineering. Institution of Engineers, Brisbane, pp 149-155

36. Murphy HM, Thomas MK, Medeiros DT, McFadyen S, Pintar KD (2016) Estimating the number of cases of acute gastrointestinal illness (AGI) associated with Canadian municipal drinking water systems. Epidemiol Infect 144:1371-1385 
37. Nygard K, Wahl E, Krogh T, Tveit OA, Bøhleng E, Tverdal A, Aavitsland $P$ (2007) Breaks and maintenance work in the water distribution systems and gastrointestinal illness: a cohort study. Int J Epidemiol 36:873-880

38. Payment P, Siemiatycki J, Richardson L, Renaud G, Franco E, Prevost M (1997) A prospective epidemiological study of gastrointestinal health effects due to the consumption of drinking water. Int J Environ Heal R 7:5-31

39. Prasad TD (2010) Design of pumped water distribution networks with storage. J Water Res PI ASCE 136: 129-132

40. Prasad TD, Tanyimboh TT (2008) Entropy based design of Anytown water distribution network. In: Van Zyl JE, llemobade AA, Jacobs HE (eds) 10th International Conference on Water Distribution Systems Analysis. Kruger National Park, South Africa, 17-20 August 2008, pp 450-461

41. Rodriguez MJ, Serodes JB, Levallois $P$ (2004) Behaviour of trihalomethanes and haloacetic acids in a drinking water distribution system. Water Res 38:4367-4382

42. Rossman LA (2000) EPANET 2 Users Manual. US Environmental Protection Agency, Water Supply and Water Resources Division, National Risk Management Research Laboratory, Cincinnati, $\mathrm{OH}$, 45268, USA

43. Saleh SHA, Tanyimboh TT (2013) Coupled topology and pipe size optimization of water distribution systems. Water Resour Manag 27:4795-4814

44. Saleh SHA, Tanyimboh TT (2014) Optimal design of water distribution systems based on entropy and topology. Water Resour Manag 28:3555-3575

45. Save-Soderbergh M, Bylund J, Malm A, Simonsson M, Toljander $J$ (2017) Gastrointestinal illness linked to incidents in drinking water distribution networks in Sweden. Water Res 122:503-511

46. Seyoum A, Tanyimboh TT (2013) Pressure-dependent multiplespecies water quality modelling of water distribution networks. The 8th International Conference of European Water Resources Association, Porto, Portugal 26-29 June 2013, pp 553-558

47. Seyoum AG, Tanyimboh TT (2014) Pressure dependent network water quality modelling. P I Civil Eng Wat M 167: 342-355

48. Seyoum AG, Tanyimboh TT (2017) Integration of hydraulic and water quality modelling in distribution networks: EPANET-PMX. Water Resour Manag 31:4485-4503

49. Seyoum AG, Tanyimboh TT, Siew, C (2014) Optimal tank design and operation strategy to enhance water quality in distribution systems. In: $11^{\text {th }}$ International Conference on Hydroinformatics. New York, 17-21 August 2014

50. Shang F, Uber JG, Rossman LA (2008) Modelling reaction and transport of multiple species in water distribution systems. Environ Sci Technol 42:808-814

51. Shang F, Uber JG, Rossman LA (2008) EPANET Multi-species Extension User's Manual. National Risk Management Research Laboratory, US EPA, Cincinnati, Ohio

52. Shannon C (1948) A mathematical theory of communication. Bell Syst Tech J 27:379-428

53. Shokoohi M, Tabesh M, Nazif S, Dini M (2017) Water quality based multi-objective optimal design of water distribution systems. Water Resour Manag 31:93-108

54. Shortridge JE, Guikema SD (2014) Public health and pipe breaks in water distribution systems: Analysis with internet search volume as a proxy. Water Res 53:26-34

55. Siew C (2011) A penalty-free multi-objective evolutionary optimization approach for the design and rehabilitation of water distribution systems. PhD thesis, University of Strathclyde, Glasgow, UK

56. Siew C, Tanyimboh TT (2012) Pressure-dependent EPANET extension Water Resour Manag 26:1477-1498

57. Siew C, Tanyimboh TT, Seyoum AG (2014) Assessment of penalty-free multi-objective evolutionary optimization approach for the design and rehabilitation of water distribution systems. Water Resour Manag 28:373-389

58. Siew C, Tanyimboh TT, Seyoum AG (2016) Penalty-free multiobjective evolutionary approach to optimization of Anytown water distribution network. Water Resour Manag 30:3671-3688

59. Skadsen J, Janke R, Grayman W, Samuels W, Tenbroek M, Steglitz B, Bahl S (2008) Distribution system on-line monitoring for detecting contamination and water quality changes. J Am Water Works Ass 100:81-94

60. Sohn J, Amy G, Cho J, Lee Y, Yoon Y (2004) Disinfectant decay and disinfection by-products formation model development: chlorination and ozonation by-products. Water Res 38:2461-2478

61. Sun Y, Petersen JN, Clement TP (1999) Analytical solutions for multiple species reactive transport in multiple dimensions. J Contam Hydrol 35:429-440

62. Tanyimboh TT (1993) An entropy-based approach to the optimum design of reliable water distribution networks. $\mathrm{PhD}$ thesis, University of Liverpool, UK

63. Tanyimboh TT, Key M (2011) Distribution network elements. In: Savic D, Banyan B (eds) Water distribution systems. ICE Publishing, London, pp 111-143

64. Tanyimboh TT, Seyoum AG (2016) Multi-objective evolutionary optimization of water distribution systems: Exploiting diversity with infeasible solutions. J Environ Manage 183:133-141

65. Tanyimboh TT, Templeman AB (1994) Discussion of redundancyconstrained minimum cost design of water distribution networks. J. Water Res. PI.-ASCE 120: 568-571

66. Tanyimboh TT, Templeman AB (1998) Calculating the reliability of single-source networks by the source head method. Adv Eng Softw 29:499-505

67. Tinker SC, Moe CL, Klein M, Flanders WD, Uber J, Amirtharajah A, Singer P, Tolbert PE (2009) Drinking water residence time in distribution networks and emergency department visits for gastrointestinal illness in Metro Atlanta. Georgia J Water Health 7:332-343

68. Twort AC, Ratnayaka DD, Brandt MJ (2000) Water supply. Arnold, London

69. Tzatchkov VG, Aldama AA, Arreguin FI (2002) Advection-dispersion-reaction modeling in water distribution networks. J. Water Res. PI.-ASCE 128: 334-342

70. US EPA (1996) Safe Drinking Water Act http://water.epa.gov/ lawsregs/rulesregs/sdwa/index.cfm. Accessed 3 August 2015

71. US EPA (2006) National Primary Drinking Water Regulations: Stage 2 Disinfectants and Disinfection By-products Rule

72. Vamvakeridou-Lyroudia LS, Walters GA, Savic DA (2005) Fuzzy multi-objective optimization of water distribution networks. J. Water Res. PI.-ASCE 131: 467-476

73. Walski TM, Brill Jr ED, Gessler J, Goulter IC, Jeppson RM, Lansey K, Lee H-L, Liebman JC, Mays L, Morgan DR, Ormsbee L (1987) Battle of the network models: Epilogue. J. Water Res. PI.-ASCE 113: 191-203

74. Walters GA, Halhal D, Savic D, Ouazar D (1999) Improved design of "Anytown" distribution network using structured messy genetic algorithms. Urban Water 1:23-38

75. Westrell T, Bergstedt O, Stenstrom T, Ashbolt N (2003) A theoretical approach to assess microbial risks due to failures in drinking water systems. Int J Environ Heal R 13:181-197

76. WHO (2011) Guidelines for Drinking-Water Quality. WHO, Geneva

77. Xu C, Goulter I (1999) Reliability-based optimal design of water distribution networks. J. Water Res. PI.-ASCE 125: 352-362

Publisher's Note Springer Nature remains neutral with regard to jurisdictional claims in published maps and institutional affiliations. 